of separate rooms seems to be justified by the benefit received.

$18 c$ De Parys Avenue

Bedford

$M K 402 T W$

\section{Impressions of South African}

psychiatry

DeAr Sirs

Professor C. L. E. Katona discussed undergraduate training in psychiatry and mentioned that the greatest exposure (eight to ten weeks) occurred at the University of Pretoria (Psychiatric Bulletin, February 1993, 17, 106-108). We would like to correct this impression, as the Department of Psychiatry under Professor W. H. Wessels, University of Natal, Durban was the first department to provide ten week exposure to clinical psychiatry spread over the fourth to sixth years of undergraduate medical training. The extended clinical training in psychiatry was introduced in 1983.

It is unfortunate that Professor Katona did not avail himself of the opportunity of visiting our medical school which has been responsible for the training of the vast majority, by far, of black doctors and black psychiatrists in South Africa.

We would like to add that we are particularly proud of the standard of psychiatry taught at our medical school.

A. J. LASICH

University of Natal

M. G. NAIR

Faculty of Medicine

Box 17039 Congella 4013

South Africa

\section{DeAR SiRs}

I am grateful to Drs Lasich and Nair for clarifying the question of undergraduate psychiatric training in the University of Natal.
I would very much have valued the opportunity of visiting their Department. Sadly, a trip as short as mine could not hope to be comprehensive-as I hope I made clear in my article.

Princess Alexandra Hospital

CORnelius Katona

Harlow, Essex

CM20 1QX

\section{A clinical dilemma and its solution}

DEAR Sirs

I would like to relate a clinical dilemma and its solution, which confronted me when on duty at my hospital.

It concerns a 37-year-old male patient with paranoid schizophrenia who had defaulted on depot medication. Having relapsed with paranoid delusions, he presented to the hospital, lying half naked on the front lawn. There he remained passively mute, refusing to respond to inquiry or instruction and, as it was bitterly cold, I was left with little option but to seek his compulsory admission. After satisfying the requirements of the Mental Health Act, which took a few hours, we were faced with a major logistical problem; he weighed 24 stone and it was a long way to the ward.

Attempts with all available muscle power failed miserably, resulting only in strained backs and bruised egos. One suspected that the patient was enjoying the experience of seeing those who earlier appeared authoritatively in control reduced to embarrassed exhaustion. When all appeared futile, a nurse came to the rescue after commandeering a wheelbarrow from the gardener and only with this were we able to affect his admission.

The patient, on making a full recovery, recalled the event with amusement and was grateful for the initiative. This highlights that no good psychiatric unit should be without an accessible, well-oiled, sturdy wheelbarrow.

University College London Medical School

CIARAN SMYTH

London WIN 8AA 